See discussions, stats, and author profiles for this publication at: https://www.researchgate.net/publication/333107966

\title{
Impacts of knowledge sharing: a review and directions for future research
}

Article in Journal of Workplace Learning · April 2019

DOI: 10.1108/JWL-07-2018-0096

2 authors, including:

C. Farhan Ahmad

Edge Hill University

16 PUBLICATIONS 36 CITATIONS

SEE PROFILE

Some of the authors of this publication are also working on these related projects:

Project The Impact of Information Literacy in the Digital Workplace (DiWIL) View project

Factors Affecting E-Learning Acceptance Among Saudi Students View project 
Impacts of Knowledge Sharing: A review and directions for future research

Citation

Farhan Ahmad, Muhaimin Karim, (2019) "Impacts of knowledge sharing: a review and directions for future research", Journal of Workplace Learning, Vol. 31 Issue: 3, pp.207230, https://doi.org/10.1108/JWL-07-2018-0096

Final version of this article is available at https://doi.org/10.1108/JWL-07-2018-0096 


\title{
Impacts of Knowledge Sharing: A review and directions for future research
}

\begin{abstract}
Purpose: Knowledge sharing contributes to the success of an organization in various ways. This paper aims to summarize the findings from past research on knowledge sharing outcomes in organizations and to suggest promising directions for future research.

Design/methodology/approach: We conducted a systematic literature review that consisted of three main phases: defining a review protocol, conducting the review, and reporting the review. The thematic analysis was conducted on 61 studies, based on which we developed a framework for understanding the impacts of knowledge sharing.

Findings: Previous research has investigated knowledge-sharing outcomes at three levels: the individual, team, and organization; specific impacts are summarized for each level. The most commonly studied factors affected by knowledge sharing are creativity, learning, and performance. Knowledge sharing is also found to have some beyondconvention work-related impacts, such as those on team climate and employees' life satisfaction. Research on the outcomes of knowledge sharing is dominated by quantitative studies, as we found only one qualitative study in this review. Based on the discussion of the results, promising avenues for further research were identified and a research agenda was proposed. More research on differential, psychological, and negative impacts, as well as interactional and methodological aspects of knowledge sharing is suggested.

Originality/value: To date, no systematic review has been conducted on the impacts of knowledge sharing. This article makes an important contribution to knowledge sharing research as it consolidates previous research and identifies a number of useful research topics that can be explored to advance the field as well as to establish the evidence-based importance of knowledge sharing.
\end{abstract}

Keywords: knowledge sharing, knowledge sharing review, knowledge sharing benefits, knowledge sharing outcomes, knowledge sharing effects, knowledge management, systematic literature review

\section{Introduction}

Knowledge sharing is one of the most fundamental activities in organizational operations. The strategic importance of knowledge is highlighted in knowledge-based view of the firm (Nickerson and Zenger, 2004). Nevertheless, the mere existence of knowledge resources does not guarantee success (Hislop, 2013; Hussein et al., 2016). To develop a sustainable competitive advantage, organizational employees must share and apply knowledge in practice (Cabrera and Cabrera, 2005; Dalkir, 2017; Nonaka et al., 2000). Previous research has emphasized the benefits of knowledge sharing in the form of cost reduction, short product development cycles, increased customer satisfaction and improved innovation and performance capabilities (Ozer and Vogel, 2015; Wang and Noe, 2010).

In the last couple of decades, research on different aspects of knowledge sharing has been increasing. One of the most important purposes of knowledge management is to systematically influence knowledge exchange, application and creation, thereby creating 
value (Kozhakhmet \& Nazri, 2017; Li et al., 2009). Consequently, success of knowledge management policies in an organization hinges on the knowledge sharing between employees and its resulting outcomes (Hislop, 2013). Due to the complexity of knowledge sharing, which is influenced by many individual, organizational, and contextual factors, a major research focus has been on the identification of factors that inhibit or support it (Mahnke et al., 2009). Consequently, one of the criticisms of knowledge-sharing research is that it focuses too much on knowledge-sharing enablers, such as technology, organizational culture, rewards, and pays comparatively less attention to the value realization of knowledge sharing (Henttonen et al., 2017).

Since the turn of the decade, interest in knowledge sharing outcomes has surged. A number of empirical studies have been conducted on the effects of knowledge sharing. This stream of research has played an important role in establishing the value of knowledge management, which sceptics once thought of as no more than a passing fad (e.g. Wilson, 2002). Moreover, it has provided concrete evidence of the benefits that individuals and organizations can obtain from their involvement and investment in knowledge sharing. However, much remains to be learned and understood about the value of knowledge sharing in organizations.

The specific purpose of this paper is to summarize the findings from past research on knowledge sharing outcomes in organizations and to suggest promising directions for future research. This paper contributes to our understanding of knowledge sharing impacts in several ways. First, the field has been growing and, to best of our knowledge, no systematic review has been conducted on the impacts of knowledge sharing to date. In contrast, a number of review papers have been published on precursors of knowledge sharing, providing a strong evidence-based understanding of knowledge sharing antecedents (e.g., Haq et al., 2016; Ipe, 2003; Wang and Noe, 2010). By consolidating previous findings, this review will help in building an evidence-based body of research on knowledge sharing outcomes. Second, existing research seems fragmented. Knowledge sharing outcomes have been investigated in fields such as information systems, strategic management, human resource management, and psychology. The present review synthesizes the current fragmented literature and provides an organizing framework based on it. Third, as the first review on the theme, it reveals the most researched topics thus far, which will help in avoiding possible repetitions while directing attention to areas of inquiry on which research is most needed.

In this review, knowledge sharing is defined as the exchange of task-related information, advice, and expertise to help others and to collaborate with others to carry out daily tasks, solve problems and develop new ideas (Ahmad, 2017). The impact of knowledge sharing refers to work-related implications and changes brought up by knowledge sharing activities of employees in an organization. We specifically focus on interpersonal knowledge sharing, that is, knowledge sharing between individuals face-toface or via online communication media, such as Skype and e-mail.

\section{Methodology}

The present literature review followed the guidelines advanced by Kitchenham (2004). Consequently, the literature review consisted of three main phases: defining a review protocol, conducting the review and reporting the review. The defined review protocol was composed of the following elements: (a) inclusions and exclusion criteria, (b) search strategy, (c) data source, (d) study selection and (e) data extraction (f) data analysis and synthesis. 


\subsection{Inclusion/exclusion criteria}

The inclusion and exclusion criteria aims to identify studies that provide direct evidence about the research question (Kitchenham, 2004). In this study, inclusion and exclusion criteria consist of four aspects. First, we include all such studies in our review that investigate the anecdotal role of knowledge sharing, whether positive or negative, toward other factors in organizations. Second, because research on knowledge sharing is interdisciplinary, the literature review is not limited to a specific discipline. Third, this review paper focuses on interpersonal knowledge sharing, which means the unit of analysis in this paper is the impacts of individual-level knowledge sharing. It is not viable to analyze knowledge sharing across teams, departments, subsidiaries, organizations and industries in one review paper. This criterion also excludes studies on knowledge transfer that has been mostly used to describe the "movement of knowledge between different units, divisions, or organizations rather than individuals"(Wang \& Noe, 2010, p.117). Fourth, only empirical studies are included in the literature review. Moreover, editorials and book reviews are excluded, as they do not include original research.

\subsection{Search strategy}

We used eight search terms; impact of knowledge sharing, benefits of knowledge sharing, role of knowledge sharing, effects of knowledge sharing, influence of knowledge sharing, knowledge sharing consequences, knowledge sharing outcomes, and knowledge sharing implications to find published papers studying the impacts of knowledge sharing. We also made a more focused search by adding commonly known impacts of knowledge sharing, such as performance, innovation, learning and creativity, into the search terms to retrieve studies that could have been missed in the first round.

\subsection{Data source}

The search terms were used to collect related studies from EBSCOhost, a database that provides access to publications in a variety of fields. Moreover, it allows using complex search strings and filters, which makes it easy to apply complex selection criteria. Therefore, it is considered a suitable choice for systematic literature reviews (e.g., Wang and Noe, 2010). To ensure inclusion of all relevant studies into our literature review analysis, we also searched for relevant studies in major digital libraries, such as Science Direct, Wiley, Springer, Sage and Google Scholar. We did not use any time period restriction and included studies published in English only.

\subsection{Study selection}

The initial search generated a result of 2,061 articles. We read the title and abstract of each article. We removed all duplicates, which considerably reduced the sample size. Then, we applied the selection criteria: the study must be empirical, published in a peerreviewed journal and focused on knowledge sharing within organizations. Consequently, 105 articles were retained. We found 22 more articles after a more focused search on knowledge sharing impacts as described in the search strategy section (Section 2.2). Overall, we had 127 articles for full text review. After thorough reading of the articles, we removed another 78 mainly due to irrelevance to our topic of interest or lack of quality. Reading the studies and their references, we found 12 more articles relevant to our objective. In the end, our final sample was composed of 61 studies. The literature 
selection process is described in the Figure 1.

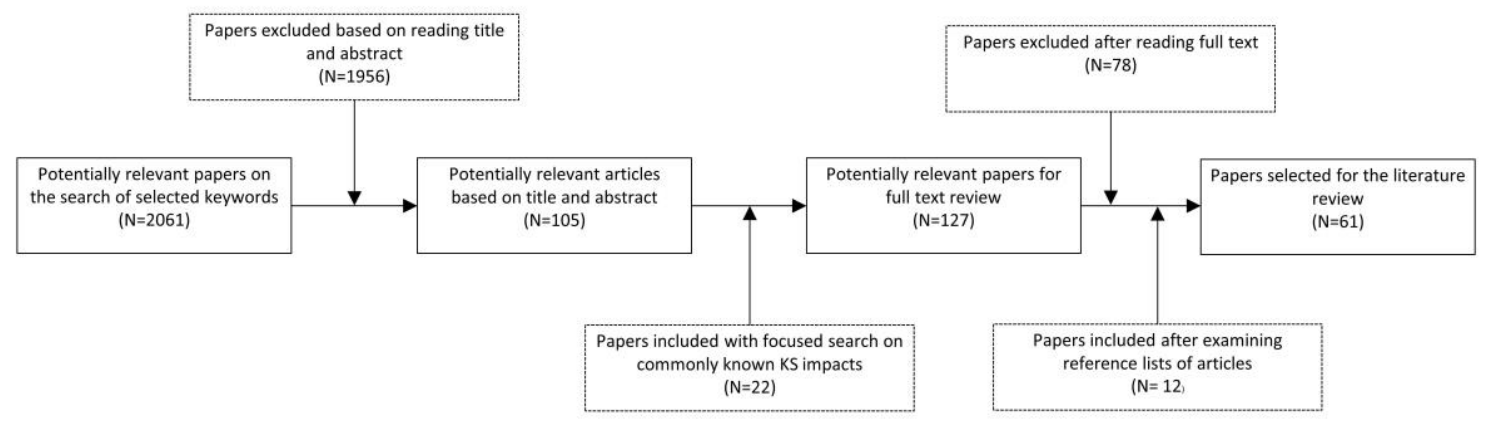

Figure 1. Study selection process.

\subsection{Data extraction}

A data extraction form was created to retrieve information on demographics, research design and knowledge sharing impacts. Both authors divided the articles among themselves and read each article, one by one. The extracted information was stored in an Excel spreadsheet.

\subsection{Data analysis and synthesis}

For data synthetization and analysis, we divided the data into two categories. The first category contained information regarding demographic and methodological attributes. It was quantitatively analyzed producing descriptive results, presented in Section 3.1. The second category contained text extracted directly from previous studies about the nature of the impacts analyzed, explanation of the impacts and key points of the study. As suggested by Zahedi et al. (2016), the thematic analysis technique, developed by Braun and Clarke (2006), was used to systematically analyze the data in the second category. The six-step process of thematic analysis is outlined below.

- Familiarization with the data: Initially, familiarization with the data was developed by reading the papers selected for review. To delve into the data further, we utilized the 'repeated reading' approach to search for meanings and patterns (Braun and Clarke, 2006). To remove any ambiguity, the extracted data was connected to its source paper to develop contextual understanding helpful in data interpretation.

- Generating initial codes: While identifying the key points in the extracted data, appropriate codes were assigned. The coding process was research question driven, i.e. we developed codes capturing different aspects of the impacts of knowledge sharing such as type of impact, nature of impact and level of impact. The studies were very elaborative in terms of outlining and defining the knowledge sharing impacts under investigation, which made it easier to assign relevant codes.

- Generating themes: After the completion of coding process, all codes were reviewed and collated to generate potential themes relevant to the research question. For example, codes, problem solving and work efficiency, were clustered under theme performance. As suggested by Braun and Clarke (2005), a visual representation of codes elaborating connections among codes and potential themes was created. Clustering helped to create main themes. 
- Reviewing themes: All of the themes were defined and common characteristics in the themes were outlined, which led to development of higher-level themes composed of many sub-themes. For example, the level of impact was a common thread connecting different themes, which led to the development of main themes, for example, individual-level impact, composed of individual performance, individual learning and creativity and individual psychological effects. Overall, this process resulted in the identification of knowledge sharing impacts explored in previous studies and potential research gaps needing further investigation.

- Producing the written analysis: Our analysis reveals knowledge sharing impacts at the individual, team and organizational level, which is presented in Section 3.2.

\section{Findings}

\subsection{Descriptive findings}

The systematic search and analysis of the papers show that the number of empirical studies investigating knowledge sharing impacts and outcomes has increased over time. Figure 2 depicts the growth in literature on knowledge sharing impacts. Overall, 76 percent of the studies were published after 2010, which shows that the impacts of knowledge sharing have attracted the most attention in the last seven years.

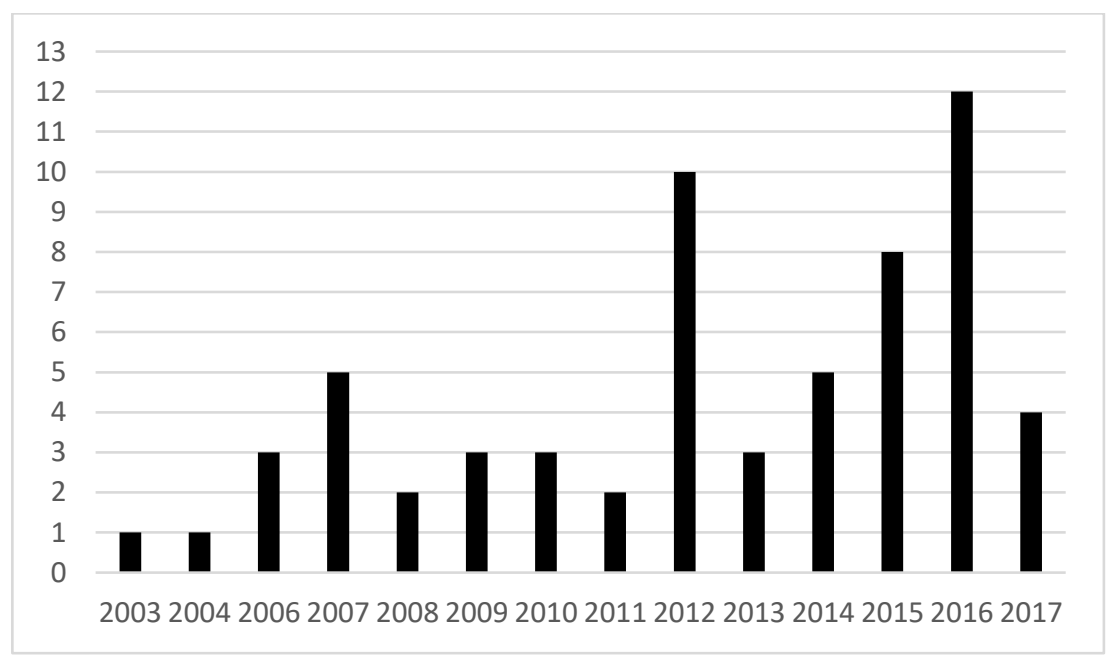

Figure 2. Growth of the empirical studies on knowledge sharing impacts in 2002-2017

The studies were published in peer-reviewed journals in different fields. As shown in Figure 3, most of the studies were published in organizational management, around 50 percent, followed by knowledge management and psychology. We found one qualitative and 60 quantitative studies. To ensure that the absence of qualitative studies in our sample was not due to our search strategy, we ran our search query one more time including the terms interviews, qualitative study, case study, and observations. Nevertheless, we did not find any new relevant studies. We determined the research methodology according to what was stated in the paper. 


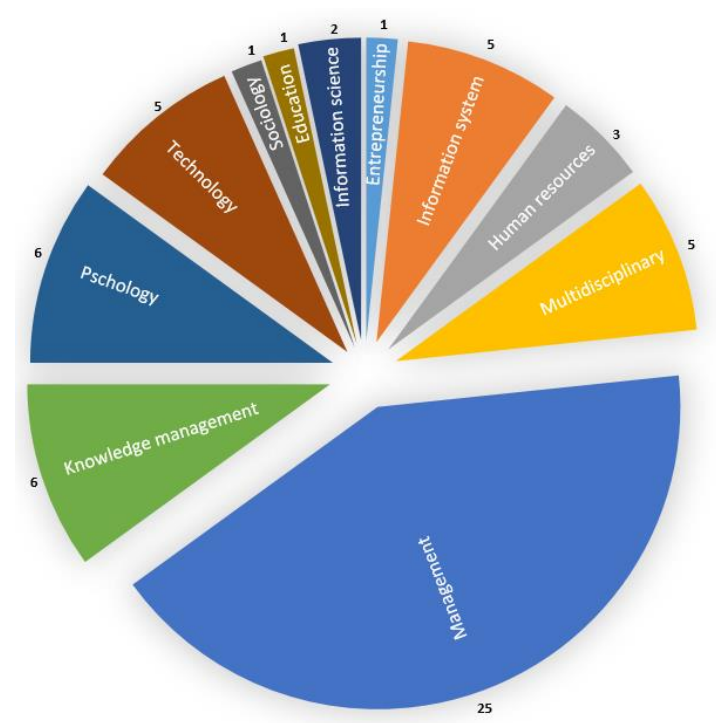

Figure 3. Distribution of studies based on types of fields

\subsection{Impacts of knowledge sharing}

This section reports the findings regarding keys impacts of knowledge sharing found in the empirical research. Table 1 provides an overview of the key effects of knowledge sharing.

\subsubsection{Individual-level impact}

At the individual level, knowledge sharing has three types of impact. It influences individual performance, learning, and creativity, and has psychological effects.

\section{Individual performance}

The empirical evidence suggests a positive effect of knowledge sharing on employee performance. The most common finding is that the utilization of collective know-how and expert opinion enabled by knowledge sharing enhances efficiency in task accomplishment, problem solving and decision making, which leads to improved employee performance (Kang et al., 2008; Masa'deh et al., 2016; Reychav \& Weisberg, 2009; Zhu, 2016).

Nevertheless, the notion that knowledge sharing enhances performance is not ubiquitous. Previous research shows that many contextual factors can influence performance outcomes of knowledge sharing. For example, an abusive supervision style and lack of management support can reduce the positive impact of knowledge sharing on employee performance (Kim \& Yun, 2015; Ozer \& Vogel, 2015; Park et al. 2015). Hostile behavior limits self-regulation resources, impairing employees' knowledge absorption and utilization capacity (Tepper, 2007). Beyond contextual conditions, personal characteristics, such as level of education (Henttonen, 2016), self-efficacy (Kim \& Yun, 2015) and personal aspiration, i.e. setting difficult goals for oneself, (Quigley et al. 2007) affect whether and to what extent employees experience improvement in performance due to knowledge sharing.

Chow (2012) examined the knowledge sharing-performance relationship in the context of individuals' network position and concluded that the performance benefits of knowledge sharing do not vary with network position of knowledge sharing participants. 
Table 1. Key effects of knowledge sharing in empirical studies

\begin{tabular}{|c|c|c|c|c|}
\hline $\begin{array}{l}\text { Impact } \\
\text { level }\end{array}$ & $\begin{array}{l}\text { Impact } \\
\text { type }\end{array}$ & Key effects & $\begin{array}{l}\text { Nature of } \\
\text { effect }\end{array}$ & Empirical studies (examples) \\
\hline \multirow{3}{*}{ : } & 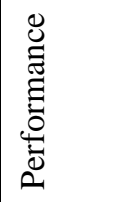 & $\begin{array}{l}\text { Task accomplishment efficiency } \\
\text { Problem solving efficiency }\end{array}$ & $\begin{array}{l}\text { Positive } \\
\text { Positive }\end{array}$ & $\begin{array}{l}\text { Masa'deh, Obeidat, \& Tarhini, } 2016 \\
\text { Kang, Kim, \& Chang, } 2008\end{array}$ \\
\hline & 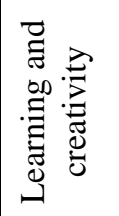 & $\begin{array}{l}\text { Innovative work behavior } \\
\text { Creative fluency and originality } \\
\text { Knowledge creation } \\
\text { Realized absorptive capacity }\end{array}$ & $\begin{array}{l}\text { Positive } \\
\text { Positive } \\
\text { Positive } \\
\text { Positive }\end{array}$ & $\begin{array}{l}\text { Radaelli et al., } 2014 \\
\text { Carmeli, Gelbard, \& Palmon, } 2013 \\
\text { Park, Song \& Lim, } 2014 \\
\text { Kang \& Lee, } 2017\end{array}$ \\
\hline & 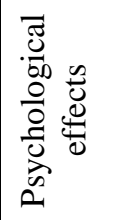 & $\begin{array}{l}\text { Job satisfaction } \\
\text { Life satisfaction } \\
\text { Intention to leave }\end{array}$ & $\begin{array}{l}\text { Positive } \\
\text { Positive } \\
\text { Negative }\end{array}$ & $\begin{array}{l}\text { Zhu, } 2016 \\
\text { Jian \& Hu, } 2016 \\
\text { Reychav \& Weisberg, } 2009\end{array}$ \\
\hline \multirow{3}{*}{$\underset{\varpi}{\Xi}$} & 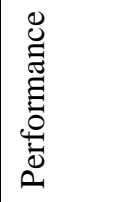 & $\begin{array}{l}\text { Work efficiency } \\
\text { Sales performance } \\
\text { Problem solving }\end{array}$ & $\begin{array}{l}\text { Positive } \\
\text { Positive } \\
\text { Positive }\end{array}$ & $\begin{array}{l}\text { Liu et al, } 2011 \\
\text { Song et al., } 2015 \\
\text { Cummings, } 2004\end{array}$ \\
\hline & : & $\begin{array}{l}\text { Creative solution and novel ideas } \\
\text { Absorptive capacity }\end{array}$ & $\begin{array}{l}\text { Positive } \\
\text { Positive }\end{array}$ & $\begin{array}{l}\text { Cheung et al., } 2016 \\
\text { Lee, Lee, \& Park, } 2014\end{array}$ \\
\hline & 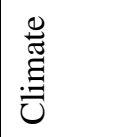 & $\begin{array}{l}\text { Trust } \\
\text { Socialization } \\
\text { Attitude toward diversity }\end{array}$ & $\begin{array}{l}\text { Positive } \\
\text { Positive } \\
\text { Positive }\end{array}$ & $\begin{array}{l}\text { Alsharo, Gregg \& Ramirez, } 2017 \\
\text { Radaelli et al., } 2014 \\
\text { Lauring \& Selmer, } 2011\end{array}$ \\
\hline \multirow{3}{*}{ 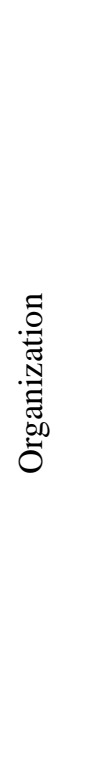 } & 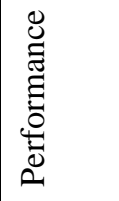 & $\begin{array}{l}\text { Financial performance (revenue, } \\
\text { return on investment) } \\
\text { New product performance }\end{array}$ & $\begin{array}{l}\text { Positive } \\
\text { Positive }\end{array}$ & $\begin{array}{l}\text { Collins \& Smith, 2006; Wang \& } \\
\text { Wang, } 2012 \\
\text { McCurtain et al., } 2010\end{array}$ \\
\hline & 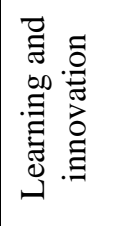 & $\begin{array}{l}\text { Ideation capability } \\
\text { Organizational absorptive } \\
\text { capacity } \\
\text { Entrepreneurial orientation and } \\
\text { corporate entrepreneurship }\end{array}$ & $\begin{array}{l}\text { Positive } \\
\text { Positive } \\
\text { Positive }\end{array}$ & $\begin{array}{l}\text { Saenz et al., } 2012 \\
\text { Kumar \& Rose, 2012; Liao et al., } \\
2007 \\
\text { De Clercq et al., 2015; Mustafa et al., } \\
2016\end{array}$ \\
\hline & 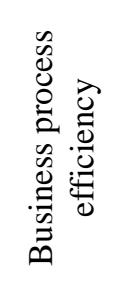 & $\begin{array}{l}\text { Strategic alignment of business } \\
\text { processes } \\
\text { Project management capability } \\
\text { Process improvement (error } \\
\text { prevention, standardization \& } \\
\text { documentation) } \\
\text { Organizational effectiveness }\end{array}$ & $\begin{array}{l}\text { Positive } \\
\text { Positive } \\
\text { Positive } \\
\text { Positive }\end{array}$ & $\begin{array}{l}\text { Pai, 2006; Kearns \& Lederer, } 2003 \\
\text { Li, Shiue, \& Chen, } 2016 \\
\text { Law \& Ngai, } 2008\end{array}$ \\
\hline
\end{tabular}

This is against expectations, as network theory suggests that central positions are advantageous in terms of time, range, access and referral and, therefore, central 
individuals should enjoy better performance outcomes than peripheral individuals (Burt, 1992).

\section{Individual learning and creativity}

When employees engage in knowledge sharing, they elaborate and externalize their knowledge (Ahmad and Widén, 2018). Many studies have found that knowledge sharing enhances innovative work behavior (Hu and Zhao, 2016), knowledge creation (Hu et al., 2009; Iqbal et al., 2015; Ma et al., 2013; Park et al., 2014), creative fluency (frequency of ideas) and creative originality (highly original ideas) (Carmeli et al., 2014), leading to effective learning and creativity (Mura et al., 2016: Zhu, 2016). As engagement in mutual discussion and exchange of ideas improve one's capability to make sense of things, knowledge sharing has also been found to enhance employees' absorptive capacity (e.g. Kang \& Lee, 2017).

Some studies show that reciprocity and individual diversity are extremely critical in the relationship between knowledge sharing, and learning and creativity (Radaelli et al., 2014). One-sided knowledge sharing means exiguous discussion and feedback, which is not sufficient for creativity that flourishes with interactive dialogue. Similarly, homogeneity among knowledge sharing participants is detrimental to learning and creativity. Employees exhibit more creativity when exposed to a range of perspectives and out-of-the-box thinking enabled by individuals with dissimilar rather than similar backgrounds (Huang et al., 2014). Overall, reciprocity and individual diversity are the only contextual factors whose role in knowledge sharing and learning relationship have been empirically investigated.

\section{Individual psychological effects}

In our review, only three studies examine the relationship between knowledge sharing and psychological aspects. As a major source of personal professional development, knowledge sharing enhances autonomy, skills utilization, and self-fulfillment. Based on a study of R\&D engineers, Zhu (2016) indicates that active knowledge sharing improves job satisfaction among employees. While drawing on social exchange and social determination theory, Jiang and $\mathrm{Hu}$ (2016) showed that knowledge sharing enhances employees' life satisfaction as it fosters quality relationships, buffers work-related stress and ameliorates work-life conflict. Another psychological aspect closely related to work and life satisfaction is intention to leave. Reychav and Weisberg (2009) showed that employees' intention to change jobs decreases with tacit and increases with explicit knowledge sharing. Nevertheless, if explicit knowledge sharing is rewarded monetarily, intention to leave the organization diminishes. As compared to tacit, explicit knowledge sharing contributes less to personal development. Therefore, employees engaging in extensive explicit knowledge sharing find it difficult to recognize learning opportunities and hence consider alternative job options.

\subsubsection{Team-level impact}

Knowledge sharing also has team-level consequences. Review of the literature shows that knowledge sharing influences team performance, creativity, and climate.

\section{Team performance}

Teams are essential elements of modern organizational work arrangements. Therefore, 
many studies have analyzed the impact of knowledge sharing on team performance (Henttonen, 2013; Huang, 2009; Srivastava et al., 2006). According to Liu, Keller, and Shih (2011), knowledge sharing between team members develops a transactive memory system that enhances work efficiency. Their study of $\mathrm{R} \& \mathrm{D}$ project teams showed that those teams that engage regularly in knowledge sharing are better equipped to deal with project-related challenges and obstacles and consequently perform better. In the Korean context, a study by Song and colleagues (2015) shows a positive relationship between teams' sales performance and knowledge sharing intensity. Cummings (2004) showed that structural diversity on a team enriches knowledge sharing by exposing the team to different sources of information and know-how, which consequently generates better performance measured in terms of effective problem solving. Nevertheless, Haas and Hansen (2007), in their study on management teams, note that lack of effort to adjust the complexity of knowledge according to the expert status of the individuals involved can reduce the positive impact of knowledge sharing on team performance. As knowledge customization improves understanding, it ensures knowledge application in novel ways (Choi, Lee, \& Yoo, 2010).

\section{Team creativity}

Teams in organizations perform many heuristic tasks without readily identifiable paths to task accomplishment (Kessel et al., 2012). Knowledge sharing among team members has been found to be an important element of team creativity and learning. Previous research shows that knowledge sharing improves teams' idea generation and absorptive capacity, which spur team creativity. In a longitudinal study, Cheung and colleagues (2016) showed that novel ideas emanate from knowledge sharing because it enables discussion of the feasibility of creative solutions. Furthermore, Lee (2014) noted that knowledge sharing between team members builds a mental model of who knows what, known as absorptive capacity, which is a critical component in team creativity.

In previous research, two contextual conditions, project complexity and instability of the environment, have been found to play an important role in the knowledge sharing and creativity relationship. A study by Wang et al., (2012) shows that for teams operating in dynamic environments, sharing task-centric knowledge, relevant to immediate problems and work-related issues, is more important for the development of the team's capability to come up with creative solutions and ideas than sharing human-centric knowledge, relevant to interpersonal issues and team objectives. Overall, empirical research on the impacts of knowledge sharing on team creativity is very limited.

\section{Team climate}

Knowledge sharing influences social climate in teams. Knowledge sharing is known to induce interaction and reciprocation, providing a platform for team socialization (Radaelli et al., 2014) and instilling trust among team members (Alsharo, Gregg and Ramirez, 2017). This also has consequences for team climate. The findings of a study by Flinchbaugh et al. (2016) confirm that intensive knowledge sharing between team members develops a positive perception of overall team collaboration climate, characterized by enhanced service quality and satisfaction.

Knowledge sharing has also been found to develop a positive attitude towards diversity in heterogeneous teams. In a Danish study, Lauring and Selmer (2011) found that knowledge sharing drives interaction between employees, which promotes openness to linguistic, visual and informational diversity. In other words, knowledge sharing builds 
a positive diversity climate in teams and in departments.

\subsubsection{Organizational-level impact}

Organizational-level implications of knowledge sharing is the most studied topic in the literature on knowledge sharing impacts. At the organizational level, knowledge sharing between employees influences organizational performance, learning and business process efficiency.

\section{Organizational performance}

Many studies have investigated the impact of knowledge sharing on organizational performance (Gomes et al., 2017; McCurtain et al., 2016, Noor et al., 2015; Oyemomi et al., 2016; Rezaei et al., 2017; Wang \& Wang, 2012).

Knowledge sharing improves organizational (financial) performance in terms of profitability, market share, return on investment and sales growth (Collins \& Smith, 2006; Gomes et al., 2017; Rezaei et al., 2017). Wang and Wang (2012) confirmed that tacit knowledge sharing enhances both financial as well as operational performance; however, explicit knowledge sharing contributes to financial performance only. Nevertheless, knowledge sharing must be in alignment with internal organizational processes to achieve positive performance outcomes (Oyemomi et al., 2016).

Most knowledge-sharing research has been conducted in the context of middleand low-level management. Although rarely researched, top-management knowledge sharing is very critical for organizational performance. McCurtain and colleagues (2010) investigated the performance outcomes of knowledge sharing between top-management employees. They showed that an organization's new product performance is a direct function of knowledge sharing in top management. As organizational top management has a holistic view of industrial dynamics and organizational capabilities, knowledge sharing in upper management can result in timely interventions leading to high organizational performance in the market.

\section{Organizational learning and innovation}

Previous empirical research shows that knowledge sharing among employees supports organizational innovation and ideation capability, absorptive capacity, and entrepreneurial orientation (Kumar and Rose (2012).

Lin (2007) showed that knowledge sharing, whether receiving it or providing it, is valuable as it erodes knowledge stickiness and sets in motion knowledge combination and reorientation processes, and leads to sustained organizational innovativeness. Wang and Wang (2012) further confirm that knowledge sharing enhances not only the quality but also the pace of learning and innovation in organizations.

Knowledge sharing is critical to the development of organizational absorptive capacity as it supports a continuous leveraging of existing knowledge to build innovative new knowledge (Khan et al., 2015; Liao et al., 2007; Iqbal et al., 2015; Yang, 2007. According to Wang et al., (2016), knowledge sharing improves organizational learning capability and thus supports knowledge embeddedness in routines and procedures and exploitation of knowledge in relationships with stakeholders.

Knowledge sharing develops entrepreneurial orientation in the organization. De Clercq and colleagues (2015) found a positive relationship between knowledge sharing and organizational entrepreneurship in SMEs. Intensive knowledge sharing enables 
organizations to develop knowledge that can be used to create new ideas, engage in experimentation, compare alternative decisions and build innovations. Mustafa, Lundmark, and Ramos (2016) also confirmed a positive relationship between knowledge sharing and organizations' entrepreneurial activities.

\section{Business process efficiency}

A desired outcome of knowledge sharing is the improvement of internal organizational practices and processes, which are considered essential for long-term organizational survival (Harmon and Trends, 2010). Therefore, previous research has empirically examined the influence of knowledge sharing on strategic alignment, project management capability and process development.

Pai (2006) found that knowledge sharing not only improves the quality of IT strategic planning processes, but also leads to the alignment of information system and business strategies, thus leading to increased efficiency in organizational operations. Kearns and Lederer (2003) also confirmed these findings in a study on knowledge-sharing behavior of chief information officers (CIOs) and chief executive officers (CEOs). Knowledge-sharing activities of CIOs and CEOs create alignment in IT and business planning processes and contribute to the development of process refinement and implementation efficiency.

Knowledge has also been found to improve organizations' project management competence. For example in the context of software projects, knowledge sharing reduces cycle time reduction (Li et al., 2016; Sáenz et al., 2012) and optimizes deployment of information systems (Shao et al., 2012).

Some studies have elaborated on the relationship between knowledge sharing and business process development (Chang et al., 2012). Law and Ngai (2008) noted that knowledge sharing supports process standardization, process simplification, coordination of activities and responsiveness in service offerings. Noor, Hajar, and Idris (2015) investigated knowledge sharing impact in the NGO context and found that knowledge sharing improves internal effectiveness by instilling clarity in project processes and activities. Overall, knowledge sharing improves business process efficiency in a number of ways.

\section{Emerging issues and future research directions}

The previous section discussed the impacts of knowledge sharing as investigated in previous research. While identifying the research gaps, the following discussion outlines emerging issues and future research directions with a particular focus on interactional, negative, differential, psychological, and methodological concerns in knowledge sharing impact research.

\subsection{Knowledge-sharing impacts from the interaction and process perspective}

Knowledge sharing is a complex process that encompasses more than the simple communication of knowledge (Ahmad, 2017). The characteristics of individuals, teams, and organizations can shape the commitment, conditions and environment of knowledgesharing processes and, consequently, their outcomes. A few studies have explored the role of external factors in knowledge-sharing outcomes. Nevertheless, the interactive potential of individual, team, and organizational characteristics remains to be explored. 


\subsubsection{Individual dispositions}

Dispositional characteristics represent the uniqueness of individuals and explain the way they tend to think and behave (Kalat, 2013). In the performance of work, individual traits are activated as suggested in the trait activation theory (Tett et al., 2013). Because productive knowledge sharing requires some creative conflict and tension (Skilton and Dooley, 2010), variance in individuals' agreeableness traits can influence the quality of knowledge sharing outcomes, such as creativity, learning and problem solving. Similarly, activation of highly neurotic traits during complex problem-solving discussion can result in fear and anxiety, lowering individuals' capacity to articulate and comprehend knowledge during knowledge sharing, thereby impeding the achievement of desired outcomes.

Another important individual disposition is sense of coherence. Having a high sense of coherence means an individual can make sense of things around him/her, show strong resilience, focus on the positive aspects of a situation and make appropriate decisions (Antonovysky, 1993; Nielsen, Matthiesen \& Einarsen, 2008), all of which play an integral role in the success of knowledge sharing interactions and their outcomes. This is an interesting area that has not been investigated before.

The dispositional perspective could be particularly useful in explaining nuances in a direct relationship between knowledge sharing and individual cognitive capacity suggested in previous studies (e.g. Carmeli, 2013). For example, employees with positive dispositions will focus on positive aspects and hence will use self-evaluations and crossvalidation triggered through knowledge sharing as opportunity for further learning. Nevertheless, the relationship may reverse if knowledge sharing participants possess highly negative personal dispositions such as negative effectivity. Therefore, future research should pay close attention to individual dispositional characteristics in the investigation of knowledge sharing impacts.

\subsubsection{Team characteristics}

In our literature review, only one study (Wang et al., 2012) investigated the role of team characteristics, team climate stability, in knowledge sharing outcomes. Teams, like individuals, possess certain characteristics that are important in the knowledge sharingoutcome transformation process.

\section{Work interdependence}

Work interdependence is considered a defining characteristic of teams and has been widely studied in the teamwork literature (Campion et al., 1996; Somech et al., 2009), but not in relation to knowledge sharing outcomes. The performance of teams characterized by high task interdependence relies on the equal and mutual contribution of team members (Campion et al., 1996), which means that not only the amount but also the diversity of the knowledge being shared will matter for performance outcomes. Moreover, the performance and creativity outcomes of knowledge sharing can vary with teams' work interdependence levels. Teams with high task interdependence can better utilize knowledge sharing, as the achievement of their goals is dependent on the collection and integration of diverse ideas. This may not be the case in low-task-interdependence teams in which individuals may not clearly identify the relevance and benefits of the knowledge being shared and hence lean on their own expertise for decision-making or problem solving. Consequently, knowledge sharing may not result in enhanced creativity. 


\section{Hierarchal diversity}

Hierarchal diversity in teams is also an important characteristic. Strong hierarchical differences can generate congruent behavior and dictate whose opinions are actualized (Cantimur et al., 2016), which means that even extensive knowledge sharing may not necessarily result in the best decisions. When power dynamics come into action, convergence on opinions and assessment of alternative views are nuanced (LePine et al., 1997), thereby influencing knowledge sharing outcomes. This proposition is very plausible in high power-distance cultures. Cross-cultural management research shows that in high power-distance contexts, subordinates show less strength in defending their arguments and are more accommodative of their superiors' views out of respect (Hofstede et al., 2010). Although previous research has analyzed the role of diversity, for example structural diversity, in knowledge sharing outcomes (e.g. Cummings, 2004), future research should pay attention to hierarchical diversity on teams and how it can influence knowledge sharing outcomes.

\subsubsection{Organizational structural characteristics}

More research is also needed to help us to understand the role of organizational characteristics in knowledge sharing outcomes. Organizational structure and environmental turbulence can influence knowledge sharing outcomes. Previous research shows that organizational survival in highly turbulent environments depends on persistent knowledge sharing enabling responsive decision-making (Keszey, 2018). However, organizational structures, in which decision-making power rests with a few individuals, experience a sharing-acting gap (Zheng, Yang, and Mclean, 2010), thereby undermining the benefits of knowledge sharing. We already know, as shown by Wang et al. (2012), that environmental dynamism influences the outcomes of knowledge sharing. Therefore, the relationship between organizational structure and knowledge sharing outcomes is intuitive and requires more empirical exploration in future research.

\subsection{Negative impacts of knowledge sharing}

Our review shows that previous research has mostly found positive impacts of knowledge sharing. Nevertheless, as pointed out by Mahnke et al. (2009), knowledge sharing is not always good. Along with benefits, it involves costs for the parties involved.

\subsubsection{Repeated collaborations}

Previous research has shown that knowledge sharing is mostly a voluntary but demanding activity that requires time, commitment of cognitive resources, and engagement (Ahmad, 2017; Cabrera and Cabrera, 2005). Individuals can end up sharing extensive amounts of knowledge, even for minor tasks, due to pervasive knowledge sharing norms. Too much knowledge sharing can lead to redundancy and cognitive costs (Foss et al., 2010). Research on mental models on teams has questioned the potential benefits of knowledge sharing, particularly when individuals engage in repeated collaborations (e.g. Haas and Hansen, 2005; Mohammed and Dumville, 2001; Skilton and Dooley, 2010). Extensive knowledge sharing in repeated collaborations can stagnate creative abrasion and team creativity over time by establishing rigid mental models, i.e. accepting views without overt discussion, evaluation and criticism due to pre-established trust acquired in past 
collaborations. Therefore, team members' collaboration history and repetition should be considered in future research on the impacts of knowledge sharing.

\subsubsection{Cognitive stress}

There is also evidence that knowledge sharing among highly differentiated individuals may not generate positive performance outcomes (Dahlin et al., 2005; Huang et al., 2014). When disparities between individuals' cognitive mental models and professional expertise are great, development of even a basic level of understanding can result in cognitive exhaustion. This can result in negative health outcomes in the form of stress. Social psychology literature shows that work engagements with diverse individuals can trigger stress, as individuals try to comprehend differences, and solve communication problems and misunderstandings. As knowledge sharing is an interaction-intensive activity, it can lead to stress and burnout, particularly when it is enforced by management's expectations and evaluations. The relationship between stress and work behaviors has been established in previous research(Colligan and Higgins, 2006; Henle and Blanchard, 2008); however, stress implications of knowledge sharing, which is an important and cognitive-intensive activity, have not been empirically analyzed thus far.

\subsubsection{Time cost}

Most interpersonal knowledge sharing in organizations takes place informally (Dalkir, 2017), which is beneficial, as it allows dealing with unanticipated problems. Nevertheless, knowledge sharing can also drain the time and resources available for other work activities, leading to work overload (Szulanski, 1996; Wang and Noe, 2010). When additional benefits are marginal, time invested on knowledge sharing beyond a certain point can inflict performance penalty. In addition, this situation is further aggravated by the perception of knowledge sharing as an extra-role activity (Cheng and Coyte, 2014). The time waste consequence of knowledge sharing has been recognized (Ahmad, 2017; Haas and Hansen, 2007); nevertheless, it requires further empirical investigation.

\subsubsection{Workplace politics}

Individuals engage in knowledge sharing with good intentions - a conception widely held in knowledge sharing research. Organizational politics theory suggests that political motivations, which may not necessarily be good, can influence work behavior (Chang et al., 2009; Miller, Rutherford, and Kolodinsky, 2008). Employees are known to strategically adjust their behavior to maximize their self-interest (Vigoda, 2002). Knowledge sharing has not been studied through the lens of workplace politics theory, even though knowledge is known as a source of power. It is highly plausible that employees can intentionally share knowledge that may not be beneficial for the accomplishment of a task. They can hold back their personal expertise for professional gains while pretending to be active knowledge sharers. Similarly, some individuals can engage in free-riding knowledge sharing by trying to benefit from the expertise of others while making little contributions themselves, leading to a public good dilemma (Cabrera and Cabrera, 2005). Such a type of knowledge sharing can intensify workplace politics and result in negative outcomes, such as negative feelings among employees, a tense work environment and hampered performance. Future research should explore the negative impacts of knowledge sharing, for example on employee relationships and work climate, using the organizational politics theory. 
Overall, a critical perspective is needed to comprehend the potential drawbacks of knowledge sharing. Research on the negative outcomes of knowledge sharing can enrich our understanding of its net impacts, particularly of when and how drawbacks outweigh benefits.

\subsection{Differential impacts of knowledge sharing}

Knowledge sharing represents a combination of some form of knowledge and a sharing activity or mechanism. Characteristics of knowledge and channel used for knowledge sharing can result in varying outcomes (Dalkir, 2017).

\subsubsection{Knowledge types}

The type of knowledge shared for a specific task can influence the achievement of individual and organizational goals. Previous studies on knowledge sharing impacts have mostly conceptualized knowledge sharing as a whole. Research on the differential impacts of sharing various types of knowledge is not only scarce but also contradictory. For example, Kessel et al. (2012) noted a positive impact of explicit knowledge sharing on innovativeness, while Reychav et al. (2012) found a negative one. Reychav et al. (2012) also showed that explicit knowledge sharing enhances employees' intention to leave the organization, whereas tacit knowledge sharing reduces it. Future research should further explore the differential impacts of different forms of knowledge sharing, as different forms of knowledge can have different outcomes.

\subsubsection{Knowledge relevance}

Explicit knowledge sharing in the form of instructions and protocol can be useful to perform standard tasks, such as software testing and maintenance and problem solving. Sharing tacit knowledge can help comprehend complex problems and develop new solutions (Reychav and Weisberg, 2009). However, for time efficiency and rapid responsiveness, sharing explicit knowledge could be more useful than sharing tacit knowledge. For example, the development of a new solution through tacit knowledge sharing will be less efficient and productive compared to sharing an already existing solution that has been designed to solve a similar problem. This shows that, for certain tasks, relevance rather than the nature of the knowledge could be more critical for the efficient accomplishment of tasks. Future research should pay close attention to what is being shared during knowledge sharing and how it feeds into outcomes.

\subsubsection{Knowledge sending vs. receiving}

While some studies conceptualize knowledge sharing as encompassing both sending and receiving, others do not make this difference and focus only on knowledge flow, regardless of direction (e.g. Kim and Yun, 2015; Law and Ngai, 2008). It would be difficult to differentiate between sending and receiving knowledge in interactive discussions; nevertheless, one's usual status as sender or receiver in the organization can influence knowledge sharing outcomes at the individual level. For example, continuous knowledge sending can be helpful in establishing one's status as an expert, but continuous receiving can be more useful in enhancing learning potential and absorptive capacity. It would be interesting to explore how individuals' general role during knowledge sharing, 
for example in team discussions, can lead to differential individual- and team-level outcomes.

\subsubsection{Knowledge sharing media}

Interpersonal knowledge sharing occurs face-to-face and via communication technologies such as e-mail and Skype. In our review, we did not find any studies exploring the potential variation in the outcomes of knowledge sharing through different channels. This is an important question, as technology-mediated knowledge sharing has become a common characteristic of today's workplaces. Ubiquitous access and flexibility offered by virtual communication channels enhance individuals' knowledge-processing capability (Barley et al., 2011) and control, leading to better knowledge-sharing outcomes. Nevertheless, technology-mediated knowledge sharing has its disadvantages. For example, Ahmad (2017) found that diversity-driven misunderstandings increase in technology-mediated knowledge sharing. Consideration of the synchronous or asynchronous nature of knowledge-sharing outcomes is also important. Real-time interactive discussion allows capitalizing on dialectical and contextualization cues and helps in the verbalization of complex cognitive thoughts, which is important for knowledge sharing quality (Ahmad, 2017). Previous research has shown that email, one of the most commonly used online tools for knowledge sharing, is a source of distraction from work due to its asynchrony, which allows people to send and receive e-mail anytime (Barley et al., 2011). Technology has inherent differential characteristics that make technology-mediated communication experiences different from face-to-face ones (Alsharo, 2017). Future research should explore how technology-mediated knowledge sharing contrasts with face-to-face knowledge sharing in terms of outcomes and achievement of individual, team and organizational goals.

\subsection{Psychological impacts of knowledge sharing}

Work practices have psychological effects (Lee et al., 2010), and knowledge sharing is no exception to this. Indeed, it is plausible that emotional consequences of individual knowledge sharing will be more blatant than those of many other work behaviors due to the crucial importance of knowledge sharing for performance and career advancement. In our review, we found only three studies that explored the psychological impacts of knowledge sharing - life satisfaction, job satisfaction and turnover intention. On the one hand, this confirms that knowledge sharing has psychological impacts and, on the other, it exposes the lack of research in this area and signals future research directions.

Future research should examine the impact of knowledge sharing on organizationbased self-esteem, i.e. the belief about one's organizational worthiness (Gardner and Pierce, 2016). Knowledge sharing is a mechanism to contribute to organizational success. As individuals put their expertise into action through knowledge sharing, they consciously or unconsciously evaluate organizational dependence on their professional expertise (Mukahi, 2016). Therefore, an impact of knowledge sharing on organizationbased self-esteem is highly likely. Nevertheless, this relationship could have certain nuances in that individuals may weigh knowledge contribution more than acquisition on their personal assessment of organizational worthiness.

Knowledge sharing could significantly influence stress. This relationship has been discussed under the negative impacts of knowledge sharing. Nevertheless, some other related psychological aspects, such as job security, person-job fit and job autonomy provide a fertile ground for future research on knowledge-sharing impacts. 


\subsection{Methodological issues}

\subsubsection{Qualitative research}

Knowledge sharing research has been mostly quantitative thus far. In one of the most comprehensive reviews of antecedents of knowledge sharing, Wang and Noe (2010) found only a small number of qualitative studies. In our review, we found only one qualitative study on knowledge sharing outcomes, that of Oyemomi et al. (2016).

This lack of qualitative research is an important gap in research on knowledgesharing outcomes. The potential reason for this gap is the sensitive nature of knowledge and temporal aspects of 'impact', which makes it difficult to secure permission to openly discuss knowledge sharing activities and to analyze their impacts that usually unfold over time. Moreover, knowledge sharing is a collaborative process, which means a valid assessment of its benefits require access to all relevant parties involved in the knowledge sharing process. Nevertheless, with all these challenges comes along the opportunity to address the depictions of "realities that cannot be reduced to a few variables"(Rynes \& Gephart, 2004, 455). Due to lack of qualitative research, we are largely unware of emergent processes that entail a transformation of knowledge sharing into potential outputs. For example, how knowledge-sharing interactions evolve during a problemsolving episode, what types of linguistic patterns are depicted, and how language and communication related aspects of knowledge sharing influence potential outcomes, are such questions that have not been addressed so far (Ahmad, 2018). Why certain knowledge sharing interactions fail and generate required output while others do not, is still largely unknown. A limited understanding of procedural, contextual and experiential aspects of the knowledge sharing process can be clearly attributed to a lack of qualitative research. Investigation into knowledge sharing interactions through observations and interviews can help understand how hidden, nevertheless important, elements of knowledge-sharing discussion, such as conflict resolution, advocacy and convergence/divergence, define knowledge sharing outcomes.

\subsubsection{Context sensitive scale}

Knowledge sharing is often measured through standard questionnaires in the form of willingness, attitude, and frequency of knowledge sharing. Although research generalizability is enhanced, standard measures face the risk of incongruence with knowledge sharing contexts and practices (DeVellis, 2016). Objectivity of measures can be improved by developing more situation-specific ones, as done by $\mathrm{Hu}$ et al. (2009). Refining focus by attending to nuances, such as timeliness of knowledge sharing, facets or types of knowledge and the quality of it, can help develop good knowledge sharing measures that provide a better understanding of its outcomes.

\subsubsection{Longitudinal research design}

Longitudinal research designs are needed to understand the dynamic processes of knowledge sharing impacts. Cross-sectional designs can show direct relationships; nevertheless, causal direction and development of events can be better analyzed through repeated data collection (Flinchbaugh et al, 2016). An important benefit of longitudinal research designs would be the possibility to analyze the reciprocal impacts of knowledge sharing on its antecedents. Those factors that influence knowledge sharing over time are themselves influenced by it and, consequently, influence knowledge sharing again, 
triggering a feedback loop. For example, impression management is a strong motivation for sharing knowledge(Gagné, 2009). Previous research has shown that individuals share knowledge to attain expert status and positive supervisor appraisals. However, if knowledge sharing results are not in alignment with motivations, individuals may withdraw from sharing activities. The same reciprocal relationship exists between organizational socialization and knowledge sharing. To unravel such dynamics, longitudinal designs with repeated surveys, observations or interviews may be of great value.

\subsubsection{Multilevel analysis}

A multilevel analysis of knowledge sharing outcomes is required in future studies. Knowledge sharing is a multilevel phenomenon that operates across boundaries and is nested within different layers of the organization. Multilevel analysis of the antecedents of knowledge sharing has been conducted before (Quigley et al., 2007); nevertheless, the multilevel impacts of knowledge sharing remain to be explored. It is possible that knowledge sharing can improve individual but not team performance or vice versa. Furthermore, employees can be tactical in knowledge sharing as they can focus on exchanging expertise and know-how to the extent that is helpful in achieving their personal rather than team goals. Multilevel analysis can be helpful in exploring the conditions and mechanisms necessary to relay and realize the value of knowledge sharing from one level to another.

\section{Conclusion and implications}

Knowledge sharing is an integral part of knowledge management, which, in turn, plays an important role in the efficient accomplishment of organizational goals. In this paper, we conducted a systematic literature review to develop a comprehensive understanding of knowledge sharing outcomes. Based on our literature review, we propose a theoretical framework (Figure 4) for research pertaining to knowledge sharing impacts. It offers an overview of the current state of the field and identifies emerging theoretical and methodological issues as discussed in the previous sections.

Overall, we can summarize four important findings from this review. First, our review shows that the impact of knowledge sharing is holistic and can be broken down into three categories: individual, team, and organizational. It shows that not only the organization but also individuals gain from engaging in knowledge sharing. Second, the most commonly studied factors influenced by knowledge sharing are creativity, learning, and performance. Third, knowledge sharing has some beyond convention work related impacts. For example, it contributes positively to team climate. As an interactionintensive activity, it enhances socialization, builds trust, encourages reciprocity and helps in the realization and appreciation of diversity. Moreover, it improves job and life satisfaction, although the evidence is limited and needs further investigation. Fourth, research on knowledge sharing impacts is dominated by quantitative studies, as we found only one qualitative study in this review. Overall, this review shows that knowledge sharing is an important organizational activity and its potential impacts cut across all organizational levels. 


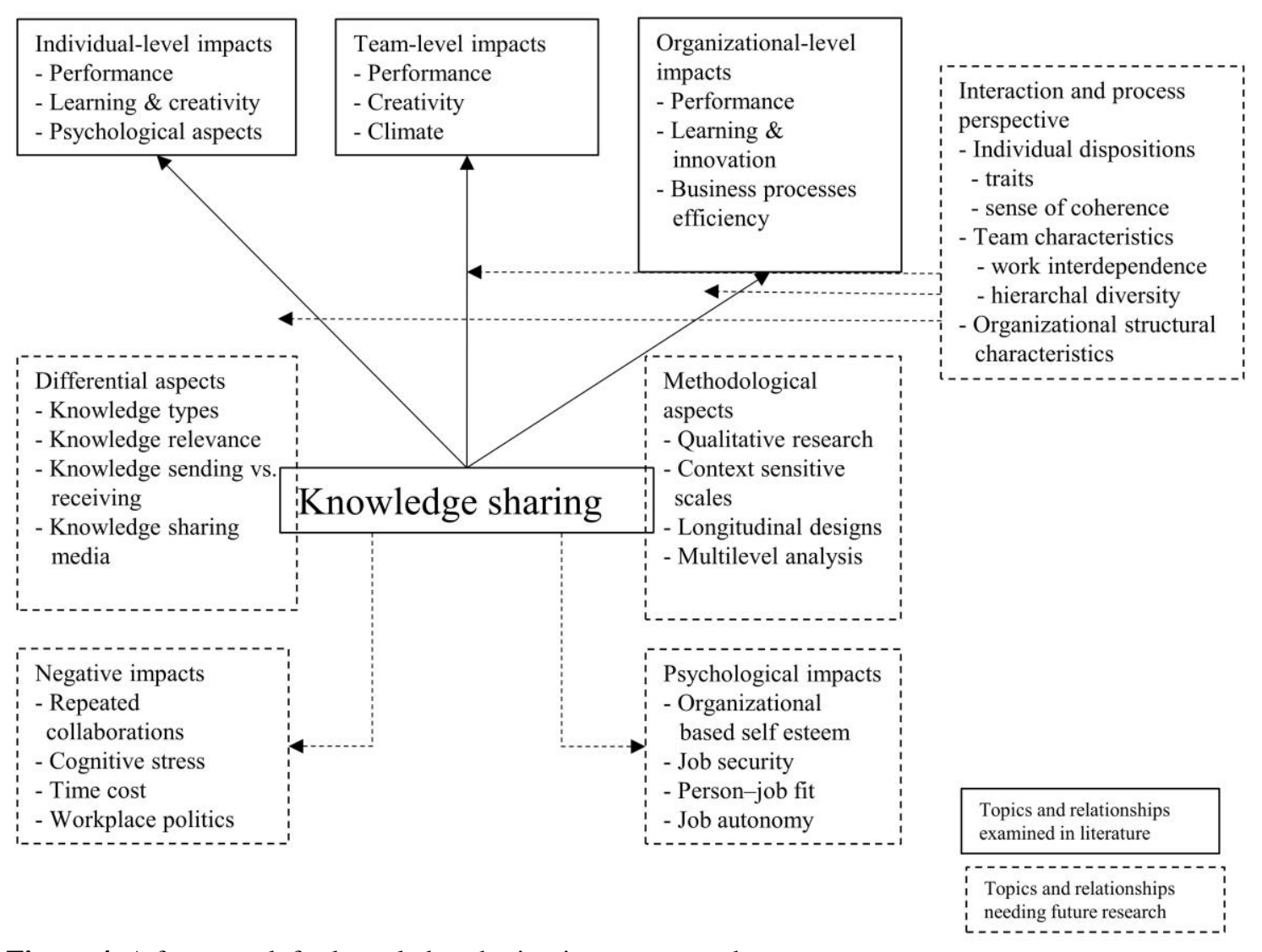

Figure 4. A framework for knowledge sharing impact research.

Although previous research has offered considerable evidence on the benefits that can be accrued from knowledge sharing, more work needs to be done. We identify five research areas that need to be explored in future research. First, research on knowledge sharing impacts should adopt an interaction and process perspective. In particular, we emphasize the importance of individual-, team-, and organizational-level characteristics. Such characteristics represent the unique traits and, thus, can determine how and what is achieved through knowledge sharing. Second, we propose that a critical perspective be taken to broaden our understanding of the net impacts of knowledge sharing, with a particular focus on its drawbacks. This review shows that previous research has tended to focus on the positive aspects of knowledge sharing. Although beneficial overall, knowledge sharing can have unintended impacts as well. For example, as a cognitiveintensive activity, knowledge sharing can lead to stress, particularly when diversity among individuals is high and convergence is difficult to achieve. Third, the differential impacts of knowledge sharing should be further investigated. Knowledge sharing has many constituents; it involves different types of knowledge as well as interaction media. Tacit and explicit knowledge sharing, technology-mediated and face-to-face knowledge sharing and knowledge sending and receiving are inherently different and can result in varying impacts. Fourth, we suggest that the psychological effects of knowledge sharing should be further explored. Knowledge sharing is a social behavior, thus intuitively connected with psychological and social consequences. Fifth, methodological improvements are suggested to better understand the impacts of knowledge sharing. Qualitative research is needed to understand processes such as knowledge sharing interaction, which conditions the influence of knowledge sharing. Moreover, longitudinal research design, which is a natural choice for developing an in-depth understanding of effect processes, needs to be operationalized in future research. 
There are some practical implications that we can draw from consistent findings in the existing literature on knowledge sharing impacts. First, knowledge sharing activities have positive psychological impacts. Employees experience not only high job satisfaction and strong commitment to the organization, but also life satisfaction. Consequently, knowledge sharing should be systematically embedded into organizations' employee well-being program. Moreover, organizations should design a knowledge management evaluation system such that, in addition to performance and innovation, effectiveness of knowledge sharing should be evaluated in terms of employee experiences and emotions related to knowledge sharing activities. Second, research has shown that knowledge sharing is beneficial at all levels - individual, team and organization. Consequently, organizations can adjust their strategies aimed at motivating employees to engage in knowledge sharing. For example, in highly individualistic cultures, individual level benefits can be advertised to encourage knowledge sharing activities in organizations. Third, many previous studies have established that knowledge sharing strongly promotes corporate entrepreneurship. Consequently, organizations, which aim to leverage current assets to develop new businesses and enter into new markets, should strongly promote knowledge sharing.

This article makes an important contribution to knowledge sharing research. This review consolidates previous research and identifies a number of useful research topics that can be explored to advance the field as well as establish the evidence-based significance of knowledge sharing. Moreover, it is a timely contribution, as it responds to recent calls for more research on knowledge sharing impacts (Henttonen et al., 2016).

\section{References ${ }^{1}$}

Ahmad, F. (2018), Knowledge sharing in multinational organizations: the impact of language. Åbo Akademi University, Åbo.

Ahmad, F. (2017), "Knowledge sharing in a non-native language context: Challenges and strategies". Journal of Information Science, Vol.24 No.2, pp. 248-264.

Ahmad, F., and Widén, G. (2018). "Knowledge sharing and language diversity in organisations: influence of code switching and convergence". European Journal of International Management, Vol.12 No.4, pp. 351-373.

*Alsharo, M., Gregg, D., and Ramirez, R. (2017), "Virtual team effectiveness: The role of knowledge sharing and trust". Information \& Management, Vol.54 No.4, pp.479-490.

Antonovsky, A. (1993), "The structure and properties of the sense of coherence scale". Social Science \& Medicine, Vol.36 No.6, pp.725-733.

Haq, M., and Anwar, S. (2016), "A systematic review of knowledge management and knowledge sharing: Trends, issues, and challenges”. Cogent Business \& Management, Vol.3 No.1, pp.1127744.

Barley, S. R., Meyerson, D. E., and Grodal, S. (2011), "E-mail as a source and symbol of stress". Organization Science, Vol.22 No.4, pp.887-906.

Burt, R. S. (1992), Structural holes: The social structure of competition. Cambridge, Mass: Harvard University Press.

Cabrera, E. F., and Cabrera, A. (2005), "Fostering knowledge sharing through people management practices". The International Journal of Human Resource Management, Vol.16 No.5, pp.720-735.

Campion, M. A., Papper, E. M., and Medsker, G. J. (1996), "Relations between work team characteristics and effectiveness: A replication and extension". Personnel psychology, Vol.49 No.2, pp.429-452.

*Carmeli, A., Gelbard, R., and Reiter-Palmon, R. (2013), "Leadership, creative problem-solving capacity, and creative performance: The importance of knowledge sharing". Human Resource Management, Vol.52 No.1, pp.95-121.

\footnotetext{
* References marked with an asterisk indicate empirical studies included in the review.
} 
Chang, C. H., Rosen, C. C., and Levy, P. E. (2009), "The relationship between perceptions of organizational politics and employee attitudes, strain, and behavior: A meta-analytic examination". Academy of Management Journal, Vol.52 No.4, pp.779-801.

*Chang, C. W., Huang, H. C., Chiang, C. Y., Hsu, C. P., and Chang, C. C. (2012), "Social capital and knowledge sharing: effects on patient safety". Journal of advanced nursing, Vol.68 No.8, pp.17931803.

Cheng, M. M., and Coyte, R. (2014), "The effects of incentive subjectivity and strategy communication on knowledge-sharing and extra-role behaviours". Management Accounting Research, Vol.25 No.2, pp.119-130.

*Cheung, S. Y., Gong, Y., Wang, M., Zhou, L., and Shi, J. (2016), "When and how does functional diversity influence team innovation? The mediating role of knowledge sharing and the moderation role of affectbased trust in a team". Human Relations, Vol.69 No.7, pp.1507-1531.

*Choi, S. Y., Lee, H., and Yoo, Y. (2010), "The impact of information technology and transactive memory systems on knowledge sharing, application, and team performance: a field study". MIS quarterly, Vol.34 No.4, pp.855-870.

*Chow, I. H. S. (2012), "The role of social network and collaborative culture in knowledge sharing and performance relations". SAM Advanced Management Journal, Vol.77 No.2, pp.24.

Colligan, T. W., and Higgins, E. M. (2006), "Workplace stress etiology and consequences". Journal of Workplace Behavioral Health, Vol.21 No.2, pp.89-97.

*Collins, C. J., and Smith, K. G. (2006), "Knowledge exchange and combination: The role of human resource practices in the performance of high-technology firms". Academy of management journal, Vol.49 No.3, pp.544-560.

*Cummings, J. N. (2004), "Work groups, structural diversity, and knowledge sharing in a global organization". Management science, Vol.50 No.3, pp.352-364.

Dahlin, K. B., Weingart, L. R., and Hinds, P. J. (2005), “Team diversity and information use". Academy of Management Journal, Vol.48 No.6, pp.1107-1123.

Dalkir, K. (2017), Knowledge management in theory and practice. MIT press.

DeVellis, R. F. (2016), Scale development: Theory and applications, Sage publications.

*De Clercq, D., Dimov, D., and Thongpapanl, N. (2015), "Structural and relational interdependence and entrepreneurial orientation in small and medium-sized enterprises: The mediating role of internal knowledge-sharing". International Small Business Journal, Vol.33 No.5, pp.514-536.

*Flinchbaugh, C., Li, P., Luth, M. T., and Chadwick, C. (2016), "Team-level high involvement work practices: investigating the role of knowledge sharing and perspective taking”. Human Resource Management Journal, Vol.26 No.2, pp.134-150.

Foss, N. J., Husted, K., and Michailova, S. (2010), “Governing knowledge sharing in organizations: Levels of analysis, governance mechanisms, and research directions". Journal of Management studies, Vol.47 No.3, pp.455-482.

Gagné, M. (2009), “A model of knowledge-sharing motivation”. Human Resource Management, Vol.48 No.4, pp.571-589.

Gardner, D. G., and Pierce, J. L. (2016), “Organization-based self-esteem in work teams”. Group Processes \& Intergroup Relations, Vol.19 No.3, pp.394-408.

*Goh, S. K., and Lim, K. Y. (2014), "Perceived creativity: the role of emotional intelligence and knowledge sharing behaviour". Journal of Information \& Knowledge Management, Vol.13 No.04.

*Gomes, J. F., Hurmelinna, P., and Olander, H. (2017), "HR Practices, Knowledge Sharing and Protection Activities, And Performance-A Moderation Model". International Journal of Innovation Management, Vol.21 No.05.

*Haas, M. R., and Hansen, M. T. (2007), "Different knowledge, different benefits: toward a productivity perspective on knowledge sharing in organizations". Strategic Management Journal, Vol.28 No.11, pp.1133-1153.

Haas, M. R., and Hansen, M. T. (2005), "When using knowledge can hurt performance: The value of organizational capabilities in a management consulting company". Strategic Management Journal, Vol.26 No.1, pp.1-24.

Harmon, P., and Trends, B. P. (2010), Business process change: A guide for business managers and BPM and Six Sigma professionals. Elsevier.

Henle, C. A., and Blanchard, A. L. (2008), "The interaction of work stressors and organizational sanctions on cyber loafing”. Journal of Managerial Issues, pp.383-400.

*Henttonen, K., Janhonen, M., and Johanson, J. E. (2013), "Internal social networks in work teams: structure, knowledge sharing and performance". International Journal of Manpower, Vol.34 No.6, pp.616-634. 
*Henttonen, K., Kianto, A., and Ritala, P. (2016), "Knowledge sharing and individual work performance: an empirical study of a public sector organisation”. Journal of Knowledge Management, Vol.20 No.4, pp.749-768.

Hofstede, G., Hofstede, G. and Minkov, M. (2010), Cultures and Organizations: Software of the Mind. New York: McGraw-Hill.

Hislop, D. (2013), Knowledge management in organizations: A critical introduction. Oxford University Press.

*Hu, B., and Zhao, Y. (2016), "Creative self-efficacy mediates the relationship between knowledge sharing and employee innovation”. Social Behavior and Personality: an international journal, 44 No.5, pp.815826.

*Hu, M. L. M., Horng, J. S., and Sun, Y. H. C. (2009), "Hospitality teams: Knowledge sharing and service innovation performance". Tourism management, Vol.30 No.1, pp.41-50.

*Huang, C. C. (2009), "Knowledge sharing and group cohesiveness on performance: An empirical study of technology R\&D teams in Taiwan”. Technovation, Vol.29 No.11, pp.786-797.

*Huang, X., Hsieh, J. J., and He, W. (2014), "Expertise dissimilarity and creativity: The contingent roles of tacit and explicit knowledge sharing". Journal of Applied Psychology, Vol.99 No.5, pp.816.

Hubbard, G. (2009), "Measuring organizational performance: beyond the triple bottom line". Business Strategy and the Environment, Vol.18 No.3, pp.177-191.

Hussein, T., Singh, K., Farouk, S., and Sohal, S. (2016), "Knowledge sharing enablers, processes and firm innovation capability", Journal of Workplace Learning, Vol.28 No.8, pp.484-495.

*Iqbal, S., Toulson, P., and Tweed, D. (2015), "Employees as performers in knowledge intensive firms: role of knowledge sharing". International Journal of Manpower, Vol.36 No.7, pp.1072-1094.

Ipe, M. (2003), "Knowledge sharing in organizations: A conceptual framework". Human Resource Development Review, Vol.2 No.4, pp.337-359.

Jerejian, A. C., Reid, C., and Rees, C. S. (2013), "The contribution of email volume, email management strategies and propensity to worry in predicting email stress among academics". Computers in Human Behavior, 29 No.3, pp.991-996.

*Jiang, Z., and Hu, X. (2016), "Knowledge sharing and life satisfaction: The roles of colleague relationships and gender". Social Indicators Research, 126 No.1, pp.379-394.

Kalat, J. W. (2013), Introduction to Psychology. Cengage Learning.

*Kang, M., and Lee, M. J. (2017), "Absorptive capacity, knowledge sharing, and innovative behaviour of R\&D employees". Technology Analysis \& Strategic Management, Vol.29 No.2, pp.219-232.

*Kang, Y. J., Kim, S. E., and Chang, G. W. (2008), "The impact of knowledge sharing on work performance: An empirical analysis of the public employees' perceptions in South Korea". Intl Journal of Public Administration, Vol.31 No.14, pp.1548-1568.

*Kearns, G. S., and Lederer, A. L. (2003), "A resource-based view of strategic IT alignment: how knowledge sharing creates competitive advantage". Decision sciences, Vol.34 No.1, pp.1-29.

Keszey, T. (2018), "Boundary spanners' knowledge sharing for innovation success in turbulent times". Journal of Knowledge Management, Vol. 22 No. 5, pp.1061-1081.

*Kessel, M., Kratzer, J., and Schultz, C. (2012), "Psychological safety, knowledge sharing, and creative performance in healthcare teams". Creativity and innovation management, Vol.21 No.2, pp.147-157.

*Khan, M. O. N., ur Rahman, S., and Khan, M. B. (2015), "The synergistic effects of knowledge sharing and learning on organisational learning: Demonstrating organisational performance". Journal of Information \& Knowledge Management, Vol.14 No.03.

*Kim, S. L., and Yun, S. (2015), "The effect of co-worker knowledge sharing on performance and its boundary conditions: An interactional perspective". Journal of Applied Psychology, Vol.100 No.2, pp.575.

Kitchenham, B. (2004), Procedures for performing systematic reviews, Keele University, 33, 1-26.

Kozhakhmet, S., \& Nazri, M. (2017), "Governing knowledge sharing behaviour in post-Soviet Kazakhstan”, Journal of Workplace Learning, Vol.29 No.3, pp.150-164.

*Kumar, N., and Che Rose, R. (2012), "The impact of knowledge sharing and Islamic work ethic on innovation capability”. Cross Cultural Management: An International Journal, Vol.19 No.2, pp.142165.

*Lauring, J., and Selmer, J. (2011), "Social climate in diverse university departments: the role of internal knowledge sharing". Educational research, 53 No.3, pp.347-362.

*Law, C. C., and Ngai, E. W. (2008), “An empirical study of the effects of knowledge sharing and learning behaviors on firm performance". Expert systems with applications, Vol.34 No.4, pp.2342-2349.

*Lee, J. C., Shiue, Y. C., and Chen, C. Y. (2016), "Examining the impacts of organizational culture and top management support of knowledge sharing on the success of software process improvement". Computers in Human Behavior, Vol.54, 462-474. 
*Lee, J., Lee, H., and Park, J. G. (2014), "Exploring the impact of empowering leadership on knowledge sharing, absorptive capacity and team performance in IT service". Information Technology \& People, Vol.27 No.3, pp.366-386.

Lee, T. R., Chen, S. Y., Wang, S. H., and Dadura, A. (2010). "The relationship between spiritual management and determinants of turnover intention". European Business Review, Vol.22 No.1, pp.102116.

LePine, J. A., Hollenbeck, J. R., Ilgen, D. R., and Hedlund, J. (1997), "Effects of individual differences on the performance of hierarchical decision-making teams: Much more than g". Journal of Applied Psychology, Vol. 82 No.5, pp.803.

Li, J., Brake, G., Champion, A., Fuller, T., Gabel, S., and Hatcher-Busch, L. (2009), "Workplace learning: the roles of knowledge accessibility and management", Journal of Workplace Learning, Vol.21 No.4, pp.347-364.

*Liao, S. H., Fei, W. C., and Chen, C. C. (2007), "Knowledge sharing, absorptive capacity, and innovation capability: an empirical study of Taiwan's knowledge-intensive industries". Journal of Information Science, Vol.33 No.3, pp.340-359.

*Lin, H. F. (2007), "Knowledge sharing and firm innovation capability: an empirical study". International Journal of Manpower, Vol.28 No.3/4, pp.315-332.

*Liu, Y., Keller, R. T., and Shih, H. A. (2011), "The impact of team-member exchange, differentiation, team commitment, and knowledge sharing on R\&D project team performance". $R \& D$ Management, Vol.41 No.3, pp.274-287.

*Lu, L., Lin, X., and Leung, K. (2012), "Goal orientation and innovative performance: The mediating roles of knowledge sharing and perceived autonomy”. Journal of Applied Social Psychology, Vol.22 No.1, pp.180-197.

*Ma, Y., Cheng, W., Ribbens, B. A., and Zhou, J. (2013), "Linking ethical leadership to employee creativity: Knowledge sharing and self-efficacy as mediators". Social Behavior and Personality: an international journal, Vol.41 No.9, pp.1409-1419.

Mahnke, V., Pedersen, T., and Venzin, M. (2009), "Does knowledge sharing pay? A multinational subsidiary perspective on knowledge outflows". In Cheng, J. L., Maitland, E., and Nicholas, S. (Eds.), Managing, Subsidiary Dynamics: Headquarters Role, Capability Development, and China Strategy, Emerald, pp. 123-149.

*MacCurtain, S., Flood, P. C., Ramamoorthy, N., West, M. A., and Dawson, J. F. (2010), "The top management team, reflexivity, knowledge sharing and new product performance: A study of the Irish software industry". Creativity and Innovation Management, Vol.19 No.3, pp.219-232.

*Masa'deh, R. E., Obeidat, B. Y., and Tarhini, A. (2016), “A Jordanian empirical study of the associations among transformational leadership, transactional leadership, knowledge sharing, job performance, and firm performance: A structural equation modelling approach". Journal of Management Development, Vol.35 No.5, pp.681-705.

Miller, B. K., Rutherford, M. A., and Kolodinsky, R. W. (2008), "Perceptions of organizational politics: A meta-analysis of outcomes". Journal of Business and Psychology, 22 No.3, pp.209-222.

Mohammed, S., and Dumville, B. C. (2001), "Team mental models in a team knowledge framework: Expanding theory and measurement across disciplinary boundaries". Journal of Organizational Behavior, Vol.22 No.2, pp.89-106.

Mukahi, T. (2016), The Moderating effects of Organization-based Self-Esteem on the Relationship between Employees' Social Network and Knowledge sharing Behaviour. In PACIS 2016 proceedings of the international conference, Chiayi, Taiwan, (p. 151).

*Mura, M., Lettieri, E., Radaelli, G., and Spiller, N. (2016), "Behavioural operations in healthcare: a knowledge sharing perspective". International Journal of Operations \& Production Management, Vol.36 No.10, pp.1222-1246.

*Mustafa, M., Lundmark, E., and Ramos, H. M. (2016), "Untangling the relationship between human resource management and corporate entrepreneurship: The mediating effect of middle managers' knowledge sharing". Entrepreneurship Research Journal, Vol.6 No.3, pp.273-295.

Nickerson, J. A., and Zenger, T. R. (2004), “A knowledge-based theory of the firm-the problem-solving perspective”. Organization Science, Vol.15 No.6, pp.617-632.

Nielsen, M. B., Matthiesen, S. B., and Einarsen, S. (2008), "Sense of coherence as a protective mechanism among targets of workplace bullying”. Journal of Occupational Health Psychology, Vol.13 No. 2, pp.128-136.

*Noor, N. H., Hajar, S. A., and Idris, M. A. (2015), "The determinant of nonprofit external and internal effectiveness: The role of knowledge sharing, collaborative culture, and beneficiary participation". Human Service Organizations: Management, Leadership \& Governance, Vol.39 No.5, pp.459-474. 
Nonaka, I., Toyama, R., and Konno, N. (2000), "SECI, Ba and leadership: a unified model of dynamic knowledge creation". Long Range Planning, 33 No.1, pp.5-34.

*Oyemomi, O., Liu, S., Neaga, I., and Alkhuraiji, A. (2016), "How knowledge sharing and business process contribute to organizational performance: Using the fsQCA approach". Journal of Business Research, Vol.69 No.11, pp.5222-5227.

*Ozer, M., and Vogel, D. (2015), "Contextualized relationship between knowledge sharing and performance in software development”. Journal of Management Information Systems, Vol.32 No.2, pp.134-161.

*Pai, J. C. (2006), "An empirical study of the relationship between knowledge sharing and IS/IT strategic planning (ISSP)", Management Decision, Vol.44 No.1, pp.105-122.

*Park, C. H., Song, J. H., Lim, D. H., and Kim, J. W. (2014), "The influences of openness to change, knowledge sharing intention and knowledge creation practice on employees' creativity in the Korean public sector context”. Human Resource Development International, Vol.17 No.2, pp.203-221.

*Park, M. J., Dulambazar, T., and Rho, J. J. (2015), “The effect of organizational social factors on employee performance and the mediating role of knowledge sharing: focus on e-government utilization in Mongolia". Information Development.

*Quigley, N. R., Tesluk, P. E., Locke, E. A., and Bartol, K. M. (2007), "A multilevel investigation of the motivational mechanisms underlying knowledge sharing and performance". Organization science, Vol.18 No.1, pp.71-88.

*Radaelli, G., Lettieri, E., Mura, M., and Spiller, N. (2014), "Knowledge sharing and innovative work behaviour in healthcare: A micro-level investigation of direct and indirect effects". Creativity and Innovation Management, Vol.23 No.4, pp.400-414.

*Reychav, I., and Weisberg, J. (2009), "Good for workers, good for companies: How knowledge sharing benefits individual employees". Knowledge and process Management, Vol.16 No.4, pp.186-197.

*Reychav, I., Stein, E. W., Weisberg, J., and Glezer, C. (2012), "The role of knowledge sharing in raising the task innovativeness of systems analysts". International Journal of Knowledge Management (IJKM), Vol.8 No.2, pp.1-22.

*Rezaei, G., Gholami, H., Shaharou, A. B. M., Zameri Mat Saman, M., Sadeghi, L., and Zakuan, N. (2017), "Shared knowledge mediated correlation between cultural excellence and organisational performance". Total Quality Management \& Business Excellence, Vol.28 No.3-4, pp.427-458.

Rynes, S., and Gephart, R. P. (2004), "From the Editors: Qualitative Research and the" Academy of Management Journal"'. The Academy of Management Journal, Vol. 47, No. 4, pp.454-462.

*Sáenz, J., Aramburu, N., and Blanco, C. E. (2012), "Knowledge sharing and innovation in Spanish and Colombian high-tech firms". Journal of Knowledge Management, Vol.16 No.6, pp.919-933.

*Shao, Z., Feng, Y., and Liu, L. (2012), "The mediating effect of organizational culture and knowledge sharing on transformational leadership and Enterprise Resource Planning systems success: An empirical study in China". Computers in Human Behavior, Vol.28 No.6, pp.2400-2413.

Skilton, P. F., and Dooley, K. J. (2010), "The effects of repeat collaboration on creative abrasion. Academy of Management Review, Vol.35 No.1, pp.118-134.

Somech, A., Desivilya, H. S., and Lidogoster, H. (2009), "Team conflict management and team effectiveness: The effects of task interdependence and team identification". Journal of Organizational Behavior, 30 No.3, pp.359-378.

*Song, C., Park, K. R., and Kang, S. W. (2015), "Servant leadership and team performance: The mediating role of knowledge-sharing climate". Social Behavior and Personality: an international journal, Vol.43 No.10, pp.1749-1760.

*Srivastava, A., Bartol, K. M., and Locke, E. A. (2006), "Empowering leadership in management teams: Effects on knowledge sharing, efficacy, and performance. Academy of Management Journal", Vol.49 No.6, pp.1239-1251.

Szulanski, G. (1996), "Exploring internal stickiness: Impediments to the transfer of best practice within the firm”. Strategic management journal, Vol.17 No.S2, pp.27-43.

Tepper, B. J. (2007), “Abusive supervision in work organizations: Review, synthesis, and research agenda. Journal of Management, Vol.33, 261-289

Tett, R. P., Simonet, D. V., Walser, B. and Brown, C. (2013), "Trait activation theory: applications, developments, and implications for person-workplace fit". In Christiansen, N.D. and Tett, R.P. Handbook of Personality at Work (pp. 71-100), New York: Routledge.

Vigoda, E. (2002), "Stress-related aftermaths to workplace politics: the relationships among politics, job distress, and aggressive behavior in organizations". Journal of Organizational Behavior, 23 No.5, pp.571-591.

Wang, S., and Noe, R. A. (2010), "Knowledge sharing: A review and directions for future research. Human Resource Management Review, Vol.20 No.2, pp.115-131. 
*Wang, M. H., Huang, C. F., and Yang, T. Y. (2012), "The effect of project environment on the relationship between knowledge sharing and team creativity in the software development context". International Journal of Business and Information, Vol.7 No.1.

*Wang, Z., and Wang, N. (2012), "Knowledge sharing, innovation and firm performance. Expert systems with applications, Vol.39 No.10, pp.8899-8908.

*Wang, Z., Sharma, P. N., and Cao, J. (2016), "From knowledge sharing to firm performance: A predictive model comparison". Journal of Business Research, Vol.69 No.10, pp.4650-4658.

Wilson, T. D. (2002), “The nonsense of knowledge management. Information research, 8 No.1, pp.8-1.

*Yang, J. T. (2007), "The impact of knowledge sharing on organizational learning and effectiveness". Journal of Knowledge Management, Vol.11 No.2, pp.83-90.

Zheng, W., Yang, B., and McLean, G. N. (2010), "Linking organizational culture, structure, strategy, and organizational effectiveness: Mediating role of knowledge management". Journal of Business Research, Vol.63 No.7, pp.763-771.

*Zhu, Y. Q. (2016), "Why and how knowledge sharing matters for R\&D engineers". $R \& D$ Management, Vol.47 No.2, pp.212-222. 